\title{
Changes in pulmonary endothelial cell properties during bleomycin-induced pulmonary fibrosis
}

\author{
Shinpei Kato ${ }^{1}$, Naoki Inui ${ }^{1,2^{*}}$ (D), Akio Hakamata ${ }^{2}$, Yuzo Suzuki $^{1}$, Noriyuki Enomoto', Tomoyuki Fujisawa', \\ Yutaro Nakamura ${ }^{1}$, Hiroshi Watanabe ${ }^{2}$ and Takafumi Suda ${ }^{1}$
}

\begin{abstract}
Background: Pulmonary fibrosis is a progressive and lethal disease characterized by damage to the lung parenchyma with excess extracellular matrix deposition. The involvement of endothelial cells in fibrosis development is unclear.

Methods: We isolated pulmonary endothelial cells, using a magnetic-activated cell sorting system, from mice with pulmonary fibrosis induced by intratracheal bleomycin. We characterized endothelial cells isolated at various times in the course of pulmonary fibrosis development.

Results: Inflammatory cell infiltration was observed at 7 days after bleomycin administration, and fibrotic changes with increased collagen content were observed on day 21. Endothelial cells were isolated at these two timepoints. Levels of von Willebrand factor, plasminogen activator inhibitor-1 and matrix metalloproteinase-12 were elevated in lung endothelial cells isolated from bleomycin-treated mice at days 7 and 21. This indicated that intratracheal bleomycin administration induced endothelium injury. Expression of fibrogenic mediators, transforming growth factor (TGF)- $\beta$, connective tissue growth factor and platelet-derived growth factor- $C$ was elevated in the cells from bleomycin-treated, compared with untreated, lungs. When endothelial cells were treated with TGF- $\beta$, $a$-smooth muscle actin (SMA) expression and collagen production were increased only in those cells from bleomycin-treated mouse lungs. Thapsigargin-induced prostaglandin $I_{2}$ and nitric oxide production, decreased in endothelial cells from bleomycin-treated mouse lungs, compared with controls, was further suppressed by TGF- $\beta$.
\end{abstract}

Conclusion: Bleomycin administration induced functional changes in lung endothelial cells, indicating potential involvement of endothelium in pulmonary fibrogenesis.

Keywords: a-SMA, Bleomycin, Endothelial cell, Fibrosis, Nitric oxide, Prostaglandin $I_{2}$, TGF- $\beta$

\section{Background}

Interstitial lung diseases (ILDs) and pulmonary fibrosis are characterized by damage to the lung parenchyma with varying patterns of inflammation and fibrosis [1]. There are hundreds of estimated etiological factors, and the pathogenesis is not completely understood [2]. It is currently believed that epithelial cell injury initiates the pathology and is followed by a mild inflammatory response [2-4]. Subsequently, fibrosis, with excess extracellular matrix deposition

\footnotetext{
* Correspondence: inui@hama-med.ac.jp

${ }^{1}$ Second Division, Department of Internal Medicine, Hamamatsu University

School of Medicine, 1-20-1 Handayama, Hamamatsu 431-3192, Japan

${ }^{2}$ Department of Clinical Pharmacology and Therapeutics, Hamamatsu

University School of Medicine, 1-20-1 Handayama, Hamamatsu 431-3192, Japan
}

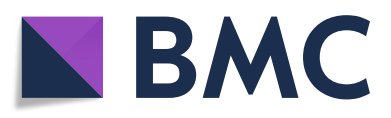

(c) The Author(s). 2018 Open Access This article is distributed under the terms of the Creative Commons Attribution 4.0 International License (http://creativecommons.org/licenses/by/4.0/), which permits unrestricted use, distribution, and reproduction in any medium, provided you give appropriate credit to the original author(s) and the source, provide a link to the Creative Commons license, and indicate if changes were made. The Creative Commons Public Domain Dedication waiver (http://creativecommons.org/publicdomain/zero/1.0/) applies to the data made available in this article, unless otherwise stated.

and collagen accumulation, occurs as a dysregulated repair process, resulting in destruction of the lung architecture, that causes ventilatory impairment and respiratory failure [1]. Among fibrotic disorders, idiopathic pulmonary fibrosis (IPF) with its pathological features of usual interstitial pneumonia (UIP), is a chronic progressive and lethal fibrotic disease with a median survival of $2-3$ years after diagnosis $[2,3,5]$. It is among the most common forms of ILDs and is widely studied in the clinical and research fields $[2,3]$.

The primary site of injury is the interstitium, forming the space between the epithelial and endothelial basement membranes [1]. Although fibroblasts are key fibrosis effectors [4, 6], fibrotic changes are caused by complex activities within several cell types including epithelial, 
inflammatory and fibrogenic effector cells [6, 7]. Pulmonary endothelial cells continuously cover the intravascular lumen and are anatomically close to epithelial and mesenchymal cells [8], suggesting that endothelium could also play an important role in the process of pulmonary fibrosis $[6,9,10]$. Takabatake et al. demonstrated pulmonary microvascular endothelial cell injury during a fibrotic process in patients with ILDs [9]. In patients with ILDs, the rate of ${ }^{123} \mathrm{I}$-metaiodobenzylguanidine washout from the lungs, reflecting pulmonary endothelial cell injury, was lower than in normal controls.

Additionally, endothelial cells may be involved in pulmonary fibrosis through two mechanisms. One is a pathway involving production of the gaseous free radical nitric oxide [11], as regulated by three isoforms of nitric oxide synthase (NOS), neuronal NOS, inducible NOS and endothelial NOS (eNOS) [12]. Nitric oxide regulates multiple biological processes and maintains respiratory homeostasis [11] but, at high levels, it can instead induce harmful inflammation and apoptosis. Several reports showed that nitric oxide is important for development of pulmonary fibrosis. Nitric oxide protects cells from oxidant-induced injury, and eNOS knockout animals have prolonged fibrosis after bleomycin exposure [13]. Yoshimura et al. showed that eNOS overexpression attenuated bleomycin-induced histological changes, lung collagen accumulation and mortality in eNOS transgenic mice [14]. They also showed that eNOS overexpression occurred mainly in endothelial cells, suggesting involvement of the endothelium, through a nitric oxide dependent mechanism, in pulmonary fibrosis development.

The other potential mechanism of endothelial cell involvement in fibrosis is their ability to transform to myofibroblasts during fibrogenesis. Myofibroblasts are defined as fibroblast-like cells expressing $\alpha$-smooth muscle actin (SMA) $[3,6,15,16]$ and are among the primary effector cells in tissue remodeling and fibrosis $[6,17]$. During lung injury, myofibroblast numbers increase and they produce high amounts of collagen and other extracellular matrix components during a repair and reconstruction process. Proposed origins of myofibroblasts include resident lung fibroblasts differentiating into activated myofibroblasts, differentiation of epithelial cells into mesenchymal cells and recruitment of circulating fibrocytes and bone marrow-derived progenitor stem cells $[6,17,18]$. Recently, transition of endothelial cells into a mesenchymal phenotype, known as the endothelial to mesenchymal transition (or endothelial-mesenchymal transition), was proposed to be another source of myofibroblasts $[17,18]$. This transition process is defined based on endothelial and mesenchymal markers and morphology. Endothelial cells lose their specific morphology and markers and acquire mesenchymal, myofibroblast-like properties. However, functional changes occurring in endothelial cells during this phenotypic alteration remain unknown.

Although no model is completely consistent with pulmonary fibrosis in humans, bleomycin is most widely used to induce pulmonary fibrosis in experimental animals $[19,20]$. After systemic delivery of bleomycin, endothelial cells were directly injured [21] and this was subsequently followed by epithelial cell injury, inflammation and fibrosis $[19,22]$. With airway administration of bleomycin, airway epithelial cells were injured initially, but the development of endothelial cell damage has not been fully elucidated. The goal of our study was to characterize pulmonary endothelial cells isolated from an in vivo mouse model of pulmonary fibrosis induced by intratracheally administered bleomycin. Endothelial cells have functional and phenotypic plasticity, influenced by their surrounding microenvironments [8]. Therefore, in particular, we investigated functional changes in the endothelial cells and their production of fibrosis-related mediators, intracellular nitric oxide and prostaglandin $\mathrm{I}_{2}\left(\mathrm{PG}-\mathrm{I}_{2}\right)$ during the process of bleomycin-induced lung injury.

\section{Methods \\ Bleomycin-induced mouse pulmonary fibrosis model} Male C57/BL6 mice 8 to 12 weeks old (20-25 g, SLC, Shizuoka, Japan) were anesthetized with intraperitoneal ketamine $(80 \mathrm{mg} / \mathrm{kg})$ and xylazine $(10 \mathrm{mg} / \mathrm{kg})$ and received a single tracheal injection of $2 \mathrm{mg} / \mathrm{kg}$ bleomycin sulfate (Nippon Kayaku, Tokyo, Japan) in $50 \mu \mathrm{L}$ sterile saline using a Microsprayer Aerosolizer (PennCentury, Philadelphia, PA, USA) on day 0. All mice were killed by cervical dislocation and lungs were harvested at day 7, 14, 21 or 28 after intratracheal bleomycin or saline treatment. This study was approved by the Animal Care and Use Committee of Hamamatsu University School of Medicine and all experiments were performed according to guidelines of this Committee.

\section{Bronchoalveolar lavage (BAL)}

After each mouse was sacrificed, a 22-gauge catheter was inserted into the trachea and $1 \mathrm{~mL}$ saline was injected and collected in three consecutive washes. After centrifugation, cell pellets were suspended, and total cells were counted using a hemocytometer in the presence of Turk's solution. Each cell suspension was smeared on a glass slide and this was stained with Diff-quick. Differential cell counting was performed manually under a light microscope. Total protein content was quantitated using a DC Protein Assay kit (Bio-Rad Laboratories, Hercules, CA, USA) [23]. Concentrations of murine transforming growth factor (TGF)- $\beta 1$ in the supernatant were evaluated using ELISA kits (R\&D systems, Minneapolis, MN, USA) according to the manufacturer's protocol. 


\section{Histopathology}

The lungs were quickly removed, inflated using a syringe, fixed in $10 \%$ buffered formalin, and embedded in paraffin. Sections $(4 \mu \mathrm{m})$ cut from embedded tissues were stained with hematoxylin-eosin (HE) and Masson's trichrome stains and observed under a light microscope.

\section{Hydroxyproline assay}

Collagen content in the mouse lungs was measured using a hydroxyproline assay. Lung tissue was homogenized with $100 \mu \mathrm{L}$ distilled water per $10 \mathrm{mg}$ tissue. $\mathrm{HCl}$ $(12 \mathrm{M}, 100 \mu \mathrm{L})$ was added to each homogenate in a pressure-tight glass tube and samples were hydrolyzed at $120{ }^{\circ} \mathrm{C}$ for $12 \mathrm{~h}$. A colorimetric assay was performed (QuickZyme Biosciences, Leiden, Netherlands) according to the manufacturer's protocol.

\section{Isolation of mouse lung endothelial cells}

After harvesting, lungs were minced with sterile scissors and incubated with $200 \mathrm{U} / \mathrm{mL}$ collagenase type 2 (Worthington, Lakewood, NJ, USA) and $100 \mathrm{U} / \mathrm{mL}$ DNase 1 (Worthington) for $30 \mathrm{~min}$ at $37^{\circ} \mathrm{C}$ in phosphate-buffered saline (PBS). Lung tissue was dissociated into single cell suspensions using a gentle MACS Dissociator (Myltenyi Biotechnology, Bergisch Gladbach, Germany), according to the manufacturer's protocol. CD45 microbeads (Myltenyi Biotec) were incubated with the single cell suspensions, enabling negative selection by magnetic cell separation using a Midi MACS separator (Myltenyi Biotec). Then CD31 microbeads (Myltenyi Biotec) were incubated in the CD45 negative cell population and positively selected by magnetic cell separation using the same separator. The $\mathrm{CD} 45^{-} \mathrm{CD} 31^{+}$ cell population thus obtained was cultured as mouse lung endothelial cells. For RNA isolation, cells were lysed in RLT buffer (Qiagen, Valencia, CA, USA). Purity of magnetically selected $\mathrm{CD} 45^{-} \mathrm{CD} 31^{+}$endothelial cells, confirmed by flow cytometry, was greater than 90\% (Additional file 1: Fig. S1).

\section{Cell culture}

Endothelial cells were cultured at a density of $1 \times 10^{6}$ cells/ well on $0.5 \%$ gelatin-coated black-walled and clear-base plates in endothelial cell basal medium-2 supplemented with 5\% fetal bovine serum (FBS) and endothelial growth factors (EGM-2 MV bullet kit; Lonza, Walkersville, MD, USA) at $37{ }^{\circ} \mathrm{C}$ with $95 \%$ air, $5 \% \mathrm{CO}_{2}$. After 3 days, non-adherent cells were removed and fresh medium was added and, subsequently, medium was changed every other day. At 7 days after sorting, cells became confluent and were used for experiments. Conditioned medium collected from the cell cultures was stored at $-80{ }^{\circ} \mathrm{C}$ for analysis of protein expression.

\section{Quantitative real time-PCR (qRT-PCR)}

Total RNA was extracted from endothelial cells using the RNeasy Mini Kit (Qiagen, Valencia, CA, USA) with homogenization using a QIA shredder (Qiagen) according to the manufacturer's instructions. The quality of total RNA samples was confirmed with a spectrophotometer (DeNovix DS-11; Scrum, Tokyo, Japan). Complementary DNA was generated from $1 \mu \mathrm{g}$ RNA using high-capacity cDNA reverse transcription kits (Applied Biosystems, Foster City, CA, USA) according to the manufacturer's instructions. qRT-PCR was performed with the THUNDERBIRD SYBR qPCR mix (TOYOBO, Tokyo, Japan) and Step One Plus (Applied Biosystems). Relative quantification of target gene transcript levels was standardized to those of the glyceraldehyde-3-phosphate dehydrogenase (GAPDH) gene and expressed as fold-changes derived from $\Delta \Delta \mathrm{Ct}$ values. Primers were from Thermo Fisher Scientific (Tokyo, Japan) and base sequences of primers are shown in Additional file 2: Table S1.

\section{Quantification of proteins}

Proteins released from endothelial cells were quantified in samples of conditioned medium using ELISA kits for TGF- $\beta 1$ (R\&D Systems), platelet-derived growth factor (PDGF)-C (Cloud-Clone Corp, Wuhan, China) or connective tissue growth factor (CTGF) (Cusabio Life Science, Wuhan, China) according to the manufacturers' protocols. Collagen content in conditioned medium was quantified using the Sircol Collagen Assay Kit (Biocolor Ltd., Carrickfergus, UK), according to the manufacturer's protocol.

\section{Measurement of intracellular nitric oxide concentrations}

Intracellular nitric oxide concentrations in endothelial cells were measured using 4- amino-5-methylamino-2', $7^{\prime}$ difluorofluorescein diacetate (DAF-FM/DA; Goryo Kayaku, Sapporo, Japan). Endothelial cells in each well were loaded with $6 \mu \mathrm{M}$ DAF-FM/DA at $37^{\circ} \mathrm{C}$ for $20 \mathrm{~min}$ in $200 \mu \mathrm{L}$ modified Tyrode's solution. After washing cells, a $200 \mu \mathrm{L}$ aliquot of $1 \mu \mathrm{M}$ thapsigargin (Sigma-Aldrich, St Louis, MO, USA) or vehicle in modified Tyrode's solution was added. Five minutes later, DAF-FM fluorescence intensities of whole cells in each well were measured with excitation and emission wavelengths of 485 and $515 \mathrm{~nm}$, respectively, using a fluorescence plate reader (Synergy H1; BioTek Instruments, Winooski, VT, USA). The fluorescence intensity ratios of thapsigargin-treated cells over those of vehicle-treated cells were calculated and compared for cells derived from both bleomycin and saline-treated mice.

\section{Measurement of prostaglandin $I_{2}\left(P G-I_{2}\right)$ production}

PG- $\mathrm{I}_{2}$ released from endothelial cells was estimated by measuring the concentration of its stable metabolite, 
6-keto $\mathrm{PGF}_{1 \alpha}$. After wash, $10 \mu \mathrm{M}$ thapsigargin (Sigma-Aldrich) or vehicle was added in $200 \mu \mathrm{L}$ modified Tyrode's solution and cells were then incubated at $37^{\circ} \mathrm{C}$ for $15 \mathrm{~min}$. The concentrations of 6-keto $\mathrm{PGF}_{1 \alpha}$ in the medium were measured with an ELISA kit (Cayman Chemical Co., Ann Arbor, MI, USA) according to the manufacturer's protocol. The concentration ratios of thapsigargin-treated over vehicle-treated cells were calculated and compared for cells derived from bleomycin-treated and saline-treated mice.

\section{Immunofluorescence staining}

For immunofluorescence staining, cells were fixed in $4 \%$ paraformaldehyde for $10 \mathrm{~min}$, incubated in blocking solution (5\% goat serum and $0.5 \%$ Triton X-100 in PBS) for $30 \mathrm{~min}$ and incubated with unconjugated anti- $\alpha$-SMA antibody (Sigma-Aldrich) and anti-CD31 antibody (Abcam, Cambridge, UK). They were then incubated with Alexa-Fluor 488 (green) conjugated anti-mouse $\operatorname{Ig} G_{2 a}$ antibody (Invitrogen, Carlsbad, CA), Alexa-Fluor 568 (red) conjugated anti-rabbit IgG antibody (Abcam) and Hoechst 33,342 (Sigma-Aldrich) antibody for $60 \mathrm{~min}$. Cells were imaged and images captured with IX83 (Olympus, Tokyo, Japan) and the ratios of $\alpha$-SMA positive cells to the total cell numbers were calculated using Image J (National Institutes of Health, Bethesda, MD, USA).

\section{Ex vivo TGF- $\beta 1$ stimulation}

Experiments were also performed, where indicated, in cultured endothelial cells stimulated for $48 \mathrm{~h}$ with TGF- $\beta 1$ (10 ng/mL, Peprotech, Rocky Hill, NJ).

\section{Statistical analysis}

All data are presented as means \pm standard error of the mean. Differences between two groups were evaluated with the Mann-Whitney's U-test. For multiple group comparisons, Tukey's test was performed. A value of $P<0.05$ was considered to be statistically significant. All values were analyzed using JMP 9.0.0 (SAS Institute Japan, Tokyo, Japan).

\section{Results}

Intratracheal bleomycin administration induced damage and subsequent pulmonary fibrosis

Intratracheal administration of bleomycin to mice using a Microsprayer Aerosolizer led to a gradual weight decrease, with peak weight loss at about day 7 , significantly lower than saline-treated mice. Gradually, the mice regained their weights. Pathological evaluation revealed patchy inflammatory cell infiltration and epithelial injury with reactive hyperplasia (Fig. 1a-e). Inflammatory cell infiltration in the alveolar walls was marked on day 7. Masson's trichrome staining showed deposits of collagen fibers on day 14 and, most prominently, on day 21 in bleomycin-treated lungs (Fig. 1f-j). Total cell counts in the BAL were significantly elevated in bleomycin-treated mice and the number of lymphocytes peaked at day 21 (Fig. 1k). The concentration of total protein and TGF- $\beta 1$ in BAL fluid was elevated over time following bleomycin administration, peaking on day 21 (Fig. 11 and Additional file 3: Fig. S2). The hydroxyproline content in the lung was increased over time after bleomycin administration (Fig. 1m). Bleomycin was reported to induce time-dependent cell injury, interstitial inflammation and deposition of extracellular matrix proteins [19]. The process is divided into two morphological phases, an inflammation predominant phase within one to two weeks after bleomycin administration and a fibrotic phase with a maximal response between the third and fourth week $[19,20]$. Our findings indicated that inflammation was predominant on day 7 and fibrosis, with collagen deposition, peaked on day 21 in the bleomycin-treated lungs. We isolated endothelial cells on days 7 and 21 after bleomycin or saline administration, to represent cells from the inflammatory and fibrotic phases, respectively.

\section{Pulmonary endothelial cells were injured by bleomycin administration}

As markers of endothelial injury, we examined expression of von Willebrand factor (vWF), plasminogen activator inhibitor-1 (PAI-1) and matrix metalloproteinase (MMP)-12 (Table 1). In endothelial cells from bleomycin-treated lungs, vWF and PAI-1 expression were elevated on day 7 and sustained on day 21 , at values significantly higher than those from saline-treated lungs on the same days. MMP-12 expression was markedly upregulated in endothelial cells from bleomycin-treated lungs. These data suggested that endothelial cells were damaged even in the mouse pulmonary fibrosis model induced by intratracheal bleomycin.

Production of intracellular nitric oxide was attenuated in endothelial cells isolated from bleomycin-treated lungs

To investigate properties of endothelial cells isolated from bleomycin-treated mouse lungs, we examined intracellular nitric oxide production in response to thapsigargin stimulation. Thapsigargin is a selective inhibitor of the endoplasmic reticulum (ER) $\mathrm{Ca}^{2+}$-ATPase and increases intracellular $\mathrm{Ca}^{2+}$ levels through plasma membrane store-operated $\mathrm{Ca}^{2+}$ channels that are activated by depletion of $\mathrm{ER}^{2}{ }^{2+}$ stores. Thapsigargin stimulation is believed to lead to production of nitric oxide and PG- $\mathrm{I}_{2}$. Intracellular nitric oxide concentrations were significantly elevated by $1 \mu \mathrm{M}$ thapsigargin stimulation in endothelial cells from either bleomycin or saline-treated mice. However, nitric oxide levels were significantly lower in endothelial cells from bleomycin-treated mice on day 21 (Fig. 2a, $p=0.0148$ ).

PG- $\mathrm{I}_{2}$ release was attenuated in endothelial cells isolated from bleomycin-treated lungs

Because of the rapid metabolism of $\mathrm{PG}-\mathrm{I}_{2}$, its concentration was estimated based on that of its stable metabolite, 6-keto 


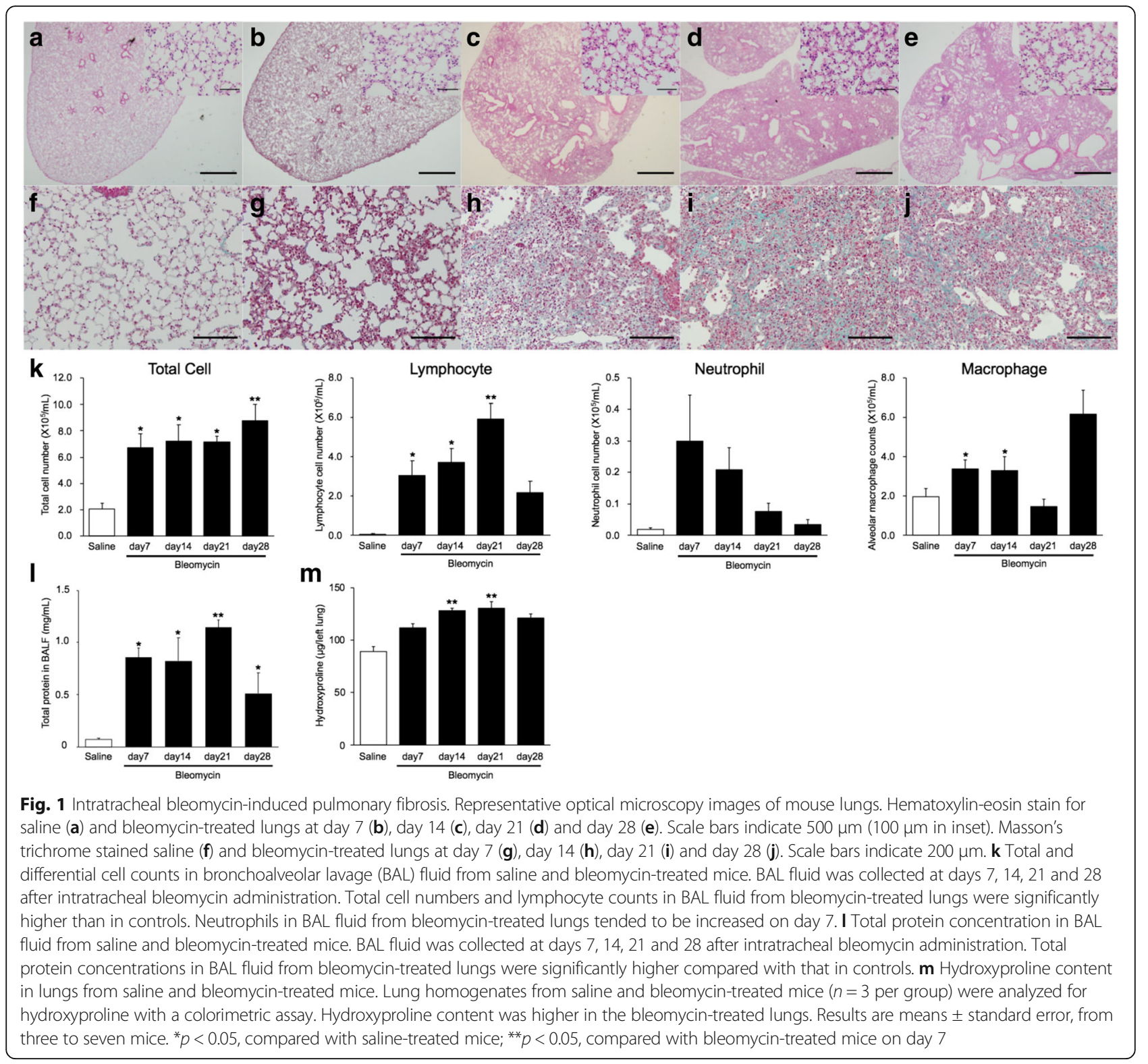

$\mathrm{PGF}_{1 \alpha}$. To investigate PG-I $\mathrm{I}_{2}$ release from endothelial cells in response to bleomycin, we therefore measured changes in 6-keto $\mathrm{PGF}_{1 \alpha}$ concentrations in the culture medium of cells stimulated with thapsigargin. Thapsigargin simulation increased 6-keto $\mathrm{PGF}_{1 \alpha}$ production in both endothelial cells from both bleomycin-treated and saline-treated mice. In the cells isolated on day 7 from bleomycin-treated mice, the thapsigargin-induced increase in 6-keto $\mathrm{PGF}_{1 \alpha}$ was similar to that in cells from saline-treated animals. However, the response to thapsigargin was significantly lower in cells isolated on day 21 from bleomycin-treated mice (Fig. $2 \mathrm{~b}, p=0.0054$ ). This suggested that endothelial cell function, assessed by thapsigargin reactivity, was attenuated in endothelial cells at the fibrotic phase.
Fibrotic mediators and NOSs in endothelial cells isolated from bleomycin-treated lungs

mRNA expression of fibrotic mediators and NOSs was evaluated (Fig. 3). Levels of TGF- $\beta 1$ mRNA were significantly elevated on day 7 compared with those in endothelial cells from saline-treated mice. On day 21, there was no significant difference in expression between endothelial cells from bleomycin and saline-treated mice. Expression of CTGF was increased in cells isolated at day 7 after bleomycin administration. Among PDGF family members, PDGF-C expression was elevated in endothelial cells from bleomycin-treated mouse lungs on days 7 and 21. Protein levels of TGF- $\beta 1$, PDGF-C and CTGF released from endothelial cells 
Table 1 Relative mRNA expression associated with endothelial cell damage

\begin{tabular}{llllll}
\hline & \multicolumn{1}{l}{ Day 7} & & Day 21 & \\
\cline { 2 - 3 } & Saline & Bleomycin & & Saline & Bleomycin \\
\hline VWF & $1.19 \pm 0.25$ & $3.09 \pm 0.15^{*}$ & & $1.33 \pm 0.22$ & $2.76 \pm 0.14^{*}$ \\
MMP-12 & $1.39 \pm 0.20$ & $18.0 \pm 0.37^{*}$ & & $0.87 \pm 0.37$ & $70.3 \pm 0.52^{*},{ }^{* *}$ \\
PAl-1 & $1.63 \pm 0.31$ & $6.05 \pm 0.28^{*}$ & & $1.72 \pm 0.14$ & $4.58 \pm 0.32^{*}$
\end{tabular}

The table shows expression of endothelial damage markers, von Willebrand factor (vWF), matrix metalloproteinase (MMP)-12 and plasminogen activator inhibitor-1 (PAI-1) in lung endothelial cells isolated from saline-treated and bleomycin-treated mice. mRNA levels were determined by quantitative real time-PCR. Total RNA was isolated from magnetically sorted $\mathrm{CD} 45^{-} \mathrm{CD} 31^{+}$ mouse lung endothelial cells at 7 and 21 days after saline or bleomycin administration. PCR was performed using three or four independently prepared cDNA samples from endothelial cells. Results were normalized to expression levels in endothelial cells from untreated lungs at day 0 and are expressed as fold-changes. Data are means \pm standard error, from three or four mice

* $p<0.05$, compared with saline-treated mice on the same day ${ }^{* *} p<0.01$, compared with bleomycin-treated mice on day 7

from bleomycin-treated mice were higher than those in cells from saline-treated mice (Fig. 4). iNOS expression was elevated in endothelial cells from bleomycin-treated mouse lungs at days 7 and 21 . eNOS levels were elevated in cells only from day 7 . The amount of collagen released into the culture medium of cells from bleomycin-treated lungs at day 21 was significantly higher than in other endothelial preparations (Fig. 5).

\section{Addition of TGF- $\beta$ to endothelial cells isolated from bleomycin-treated lungs}

To further explore the functional and phenotypic changes of endothelial cells in bleomycin-treated lungs, we performed additional studies in which TGF- $\beta$ was added to endothelial cells. The collagen content from lung endothelial cells treated with TGF- $\beta$ was significantly higher than in cells without TGF- $\beta$ treatment (Fig. 5). In endothelial cells from saline-treated mouse lungs, adding TGF- $\beta$ did not increase collagen content. Next, we fluorescently stained endothelial cells for $\alpha$-SMA and CD31 and observed them with a fluorescence microscope (Fig. 6). Even without TGF- $\beta 1$, endothelial cells from bleomycin-treated mouse lungs had increased $\alpha$-SMA staining. The percentage of $\alpha$-SMA positive cells on day 21 was $7.0 \%$, significantly higher than in cells from saline-treated mouse lungs on the same day $(2.1 \%, p<0.05)$. When stimulated with TGF- $\beta 1$, approximately one third of bleomycin-treated lung endothelial cells had elevated $\alpha$-SMA staining. The percentage of cells with positive staining was significantly higher in cells from bleomycin-treated than from vehicle-treated lungs (Fig. 6, $p<0.01$ ). These changes in $\alpha$-SMA levels were confirmed at the mRNA level (Table 2 and Fig. 3). Interestingly, TGF- $\beta$ did not increase the percentage of $\alpha$-SMA-positive cells in lung endothelial cells from saline-treated mice. Regarding the function of the endothelial cells, TGF- $\beta$ addition to endothelial cells from day 21 after bleomycin treatment decreased their
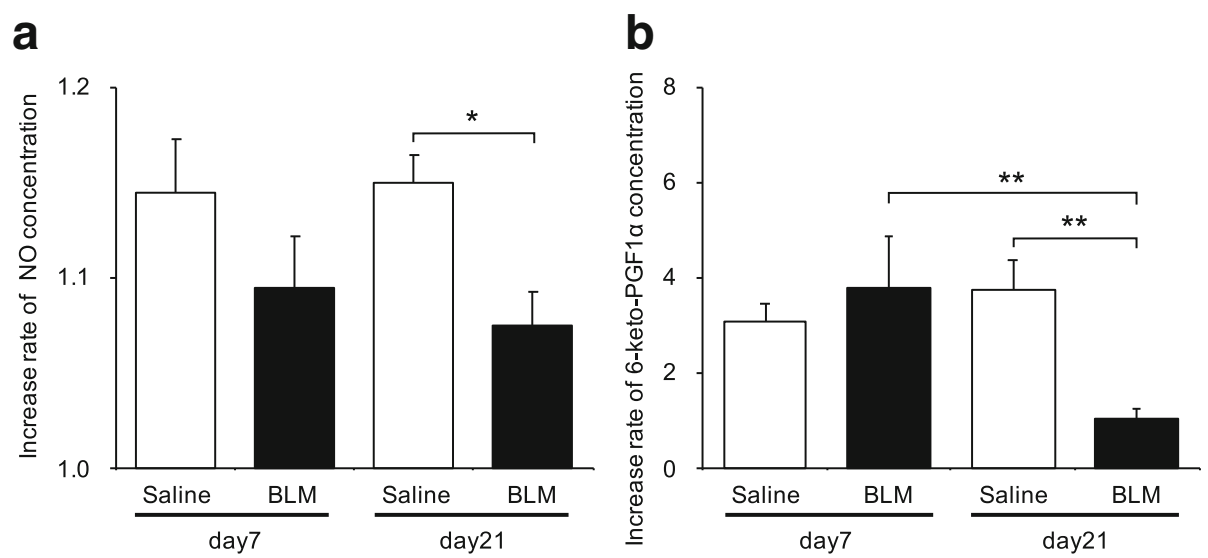

Fig. 2 Functional performance of endothelial cells from bleomycin-treated lungs, assessed by response to thapsigargin. a Intracellular nitric oxide concentrations in endothelial cells were measured using DAF-FM/DA. Thapsigargin $(1 \mu \mathrm{M})$ was added and the DAF-FM fluorescence intensity in whole cells was measured at $515 \mathrm{~nm}$. The fluorescence intensity ratio indicates the relative fluorescence intensity of intracellular nitric oxide in thapsigargin-treated endothelial cells over that in untreated endothelial cells. The fluorescence intensity ratio of intracellular nitric oxide was significantly attenuated in endothelial cells from bleomycin-treated lungs at day 21, compared with in saline-treated lungs. b 6-Keto PGF 1 a released from endothelial cells. The concentration of 6-keto PGF 1 in the culture medium was measured by ELISA after incubation of endothelial cells with $10 \mu \mathrm{M}$ thapsigargin. The relative concentration ratio indicates the concentration of 6-keto $\mathrm{PGF}_{1 \mathrm{a}}$ in thapsigargin-treated endothelial cells over that in untreated cells and these ratios were compared for cells from saline and bleomycin-treated mice. Relative rates of 6-keto PGF 19 production were significantly attenuated in thapsigargin-stimulated endothelial cells from bleomycin-treated lungs, compared with in those from saline-treated lungs, both isolated on day 21. These levels were also attenuated relative to those in endothelial cells from bleomycin-treated lungs that were not stimulated by thapsigargin at the same day. Data are means \pm standard error from three or four mice. ${ }^{*} p<0.05,{ }^{* *} p<0.01$ 


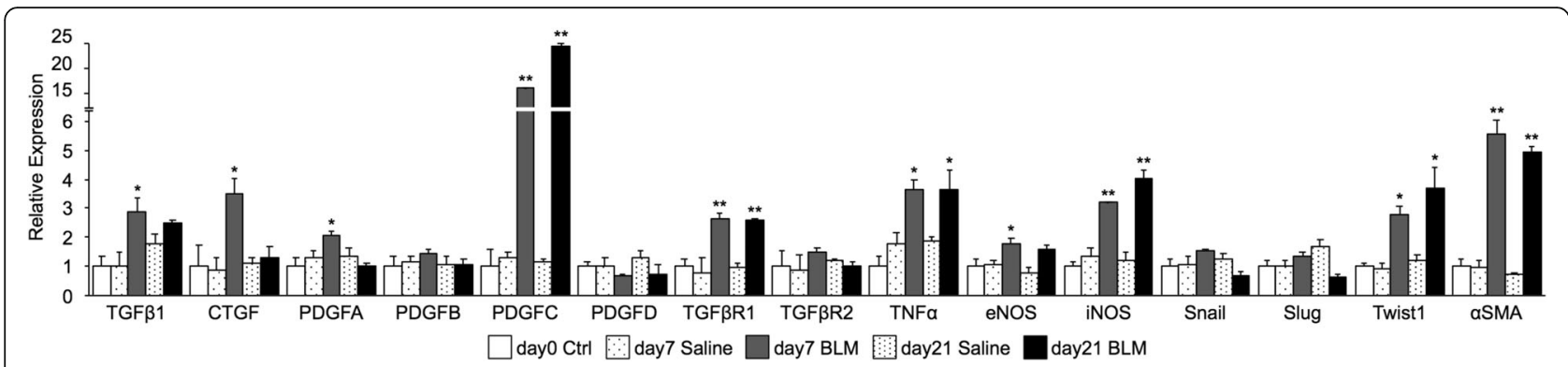

Fig. 3 Expression of mediators, determined by quantitative real-time PCR. Levels of mRNA for various mediators were compared in endothelial cells from saline and bleomycin-treated mouse lungs. Quantitative real-time PCR was performed using three or four independently prepared cDNA samples from endothelial cells harvested from saline or bleomycin-treated lungs on days 7 and 21 . Gene expression was calculated as $\Delta$ Ct, the $\mathrm{Ct}$ of a gene of interest minus the $\mathrm{Ct}$ of GAPDH from the same sample. Results were normalized to expression levels in endothelial cells from untreated lungs at day 0 and are means from three experiments. Data are means \pm standard error of the mean for three or four mice. ${ }^{*} p<0.05$, ${ }^{* *} p<0.01$, compared with saline-treated mice

intracellular nitric oxide concentrations to values lower than in the same cells without TGF- $\beta$ (Fig. 7a). Similarly, the thapsigargin-induced increase in 6-keto $\mathrm{PGF}_{1 \alpha}$ in endothelial cells from bleomycin-treated mice was attenuated by TGF- $\beta$ (Fig. 7b). We also evaluated mRNA expression of PDGF-C, CTGF, iNOS, eNOS and Twist-1 in cells after TGF- $\beta$ treatment (Table 2). After TGF- $\beta$ treatment, PDGF-C expression in endothelial cells was increased and that of iNOS and eNOS was decreased. Expression of Twist-1 in lung endothelial cells, already increased if they were isolated after bleomycin treatment, was further increased by TGF- $\beta$.

\section{Discussion}

In this study, we isolated endothelial cells from lung tissues with bleomycin-induced fibrosis and investigated the functional changes occurring during fibrogenesis. Levels of vWF, MMP-12 and PAI-1 were elevated, indicating continuous endothelium injury, on day 7 and as late as day 21 .
Expression of mediators related to fibrosis and collagen production was also increased. $\mathrm{PG}-\mathrm{I}_{2}$ and nitric oxide production in response to thapsigargin, representing intrinsic functions of endothelium, were sustained in endothelial cells harvested at 7 days after bleomycin administration but were lower in those isolated at 21 days. In endothelial cells stimulated with TGF- $\beta$, $\alpha$-SMA expression and collagen production were increased in cells from bleomycin-treated, compared with vehicle-treated, mouse lungs. TGF- $\beta$ treatment also decreased thapsigargin-induced PG- $\mathrm{I}_{2}$ and nitric oxide production by the cells. Bleomycin exposure induced functional changes in lung endothelial cells, potentially related to their involvement in fibrogenesis.

Various mediators, including tumor necrosis factor- $\alpha$ (TNF- $\alpha$ ) [24], CTGF [25], interleukin (IL)-18 and IL-1 $\beta$ [26], are believed to mediate bleomycin-induced pulmonary inflammation and fibrosis. These mediators are expressed primarily in alveolar macrophages, epithelial cells, fibroblasts and immune cells. In the lungs, TGF- $\beta$, the major fibrotic cytokine, is produced by a wide variety
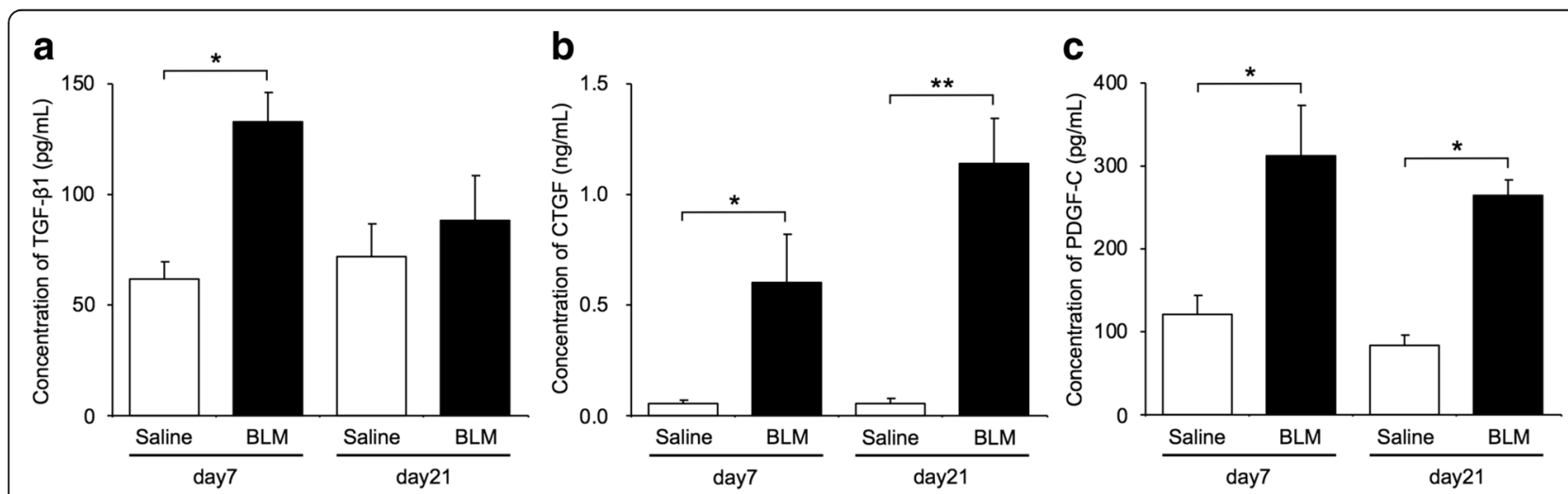

Fig. 4 Fibrotic mediator proteins released from endothelial cells. Protein levels of TGF- $\beta 1$ (a), CTGF (b) and PDGF-C (c) were quantified by ELISA. Concentrations of TGF- $\beta 1$, CTGF and PDGF-C were significantly higher in the culture medium of endothelial cells from bleomycin-treated lungs, compared with those from saline-treated lungs. Data are means \pm standard error of the mean for three to six mice. ${ }^{*} p<0.05,{ }^{* *} p<0.01$, compared with saline-treated mice 


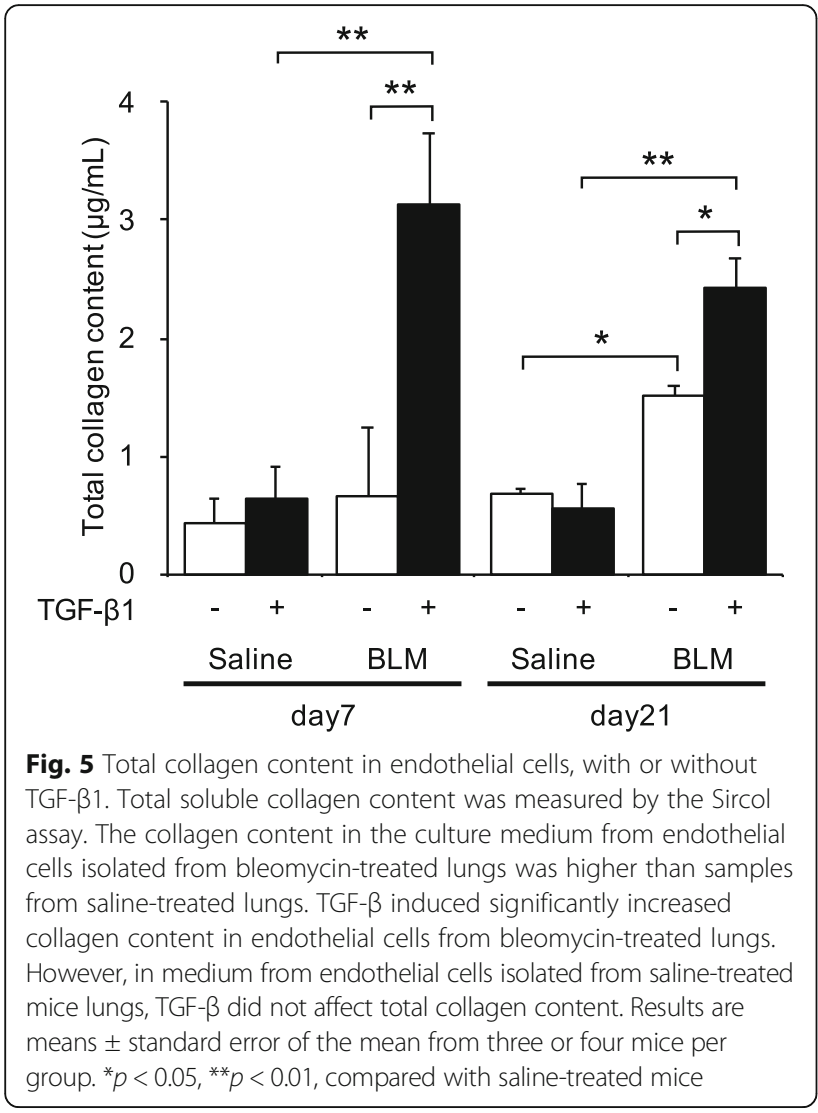

of cell types, including alveolar macrophages, neutrophils, activated alveolar epithelial cells, fibroblasts and myofibroblasts [18, 27-31]. Zhang et al. showed that fibroblasts, myofibroblasts and eosinophils strongly express TGF- $\beta$ mRNA and protein in endotracheal cells from rats with bleomycin-induced pulmonary fibrosis [32]. However, their study did not focus on endothelial cells. Yan et al. purified endothelial cells from rats using a tissue explant method of bleomycin-induced fibrosis and identified endothelial cells by vWF immunofluorescence and cell morphology. Endothelial cells from the bleomycin-treated rats showed increased secretion of CTGF from days 7 to 28 [33]. Leach et al. administered bleomycin subcutaneously and then purified endothelial cells from the treated animals by cell sorting using flow cytometry [21]. In endothelial cells harvested on the fourth week after bleomycin administration, there was overexpression of the fibrotic mediators, CTGF, PAI-1 and osteopontin. These investigators proposed that, because endothelial injury markers were elevated between the first and second week, endothelial cell injury preceded development of fibrosis. In our study, gene expression of the fibrotic mediators, CTGF and TGF- $\beta$, was elevated in endothelial cells at 7 days after bleomycin administration. In addition, we confirmed that bleomycin treatment increased expression of these mediators at the protein level. There were differences in the timing of endothelial injury and fibrotic markers elevations. In our study, levels of endothelium injury markers, VWF, MMP-12 and PAI-1, and fibrotic mediators were elevated on day 7 and sustained on day 21. In the study of Leach et al., levels of endothelium injury markers were elevated on day 28 after bleomycin administration and there was no difference in the
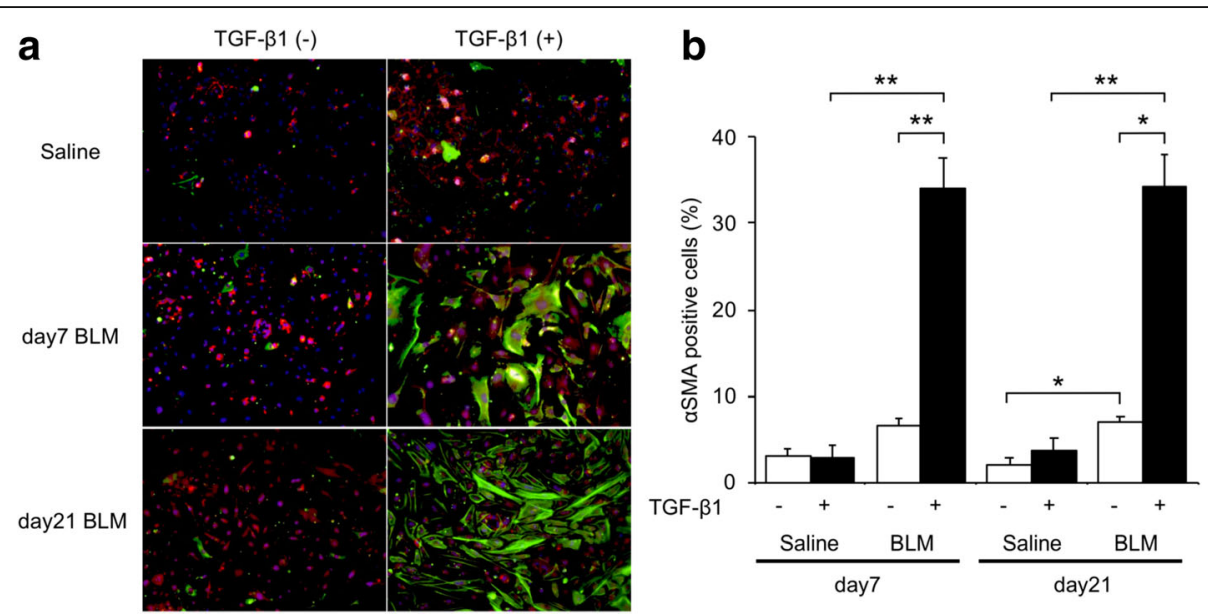

Fig. 6 TGF- $\beta 1$-induced increased a-SMA staining in endothelial cells from bleomycin-treated lungs. a Shown are representative fluorescence microscopy images of endothelial cells from bleomycin-treated lungs, cultured with or without TGF- $\beta 1$. The a-SMA (green) and CD31 (red) stained images were merged with those showing a nuclear stain (Hoechst, blue). b Comparison of the percentage of a-SMA positive endothelial cells from saline and bleomycin-treated lungs, cultured with or without TGF- $\beta 1$. Cells were imaged and images captured with IX83 and the percentage of a-SMA positive cells expressed as the percentage of total cell number, estimated from Hoechst 33,342 nuclear staining. The percentage of a-SMA positive cells was significantly elevated in cells from bleomycin-treated lungs and in any endothelial cells treated with TGF- $\beta 1$, compared with in the corresponding controls. TGF- $\beta 1$ treatment further enhanced the percent of a-SMA stained cells in lung endothelial cultures from bleomycin-treated mice. Data are means \pm standard error, from three to four mice. ${ }^{*} p<0.05,{ }^{* *} p<0.01$ 
Table 2 Relative mRNA expression in endothelial cells, with and without TGF- $\beta 1$

\begin{tabular}{lllll}
\hline \multicolumn{3}{c}{ Day 7 } & \multicolumn{3}{l}{ Day 21 } \\
\hline TGF- $\beta 1$ & - & + & - & + \\
CTGF & $3.49 \pm 0.54$ & $4.84 \pm 0.10$ & $1.27 \pm 0.41$ & $2.61 \pm 0.14$ \\
PDGF-C & $16.0 \pm 0.07$ & $22.8 \pm 0.29$ & $24.4 \pm 0.37$ & $79.5 \pm 0.56^{*}$ \\
eNOS & $1.75 \pm 0.21$ & $0.16 \pm 0.42^{* *}$ & $1.59 \pm 0.11$ & $0.07 \pm 0.71^{* *}$ \\
iNOS & $3.20 \pm 0.02$ & $0.24 \pm 0.32^{* *}$ & $4.05 \pm 0.28$ & $0.11 \pm 0.75^{* *}$ \\
Twist-1 & $2.76 \pm 0.31$ & $7.95 \pm 0.23^{* *}$ & $3.71 \pm 0.72$ & $14.3 \pm 0.59^{*}$ \\
a-SMA & $5.60 \pm 0.80$ & $18.6 \pm 0.16^{*}$ & $4.97 \pm 0.29$ & $35.8 \pm 0.29^{*}$
\end{tabular}

The table shows gene expression of connective tissue growth factor (CTGF), platelet-derived growth factor (PDGF)-C, inducible nitric oxide synthase (iNOS), endothelial nitric oxide synthase (eNOS), Twist-1, and a-smooth muscle actin (a-SMA) in lung endothelial cells from bleomycin-treated mice, with and without TGF- $\beta 1(10 \mathrm{mg} / \mathrm{mL})$ treatment. mRNA levels were determined by quantitative real time-PCR. Total RNA was isolated from endothelial cells at 7 and 21 days after bleomycin administration. PCR was performed using three to four independently prepared cDNA samples from endothelial cells. Results were normalized to expression levels in endothelial cells from untreated lungs at day 0 and are expressed as fold-changes. Data are means \pm standard error of the mean, from three or four mice ${ }^{*} p<0.05$ versus cells without TGF- $\beta 1$ ${ }^{* *} p<0.01$ versus cells without TGF- $\beta 1$ on day 21 and with TGF- $\beta 1$ on day 7

expression of TGF- $\beta 1$ mRNA between endothelial cells from bleomycin-treated and saline-treated lungs. These differences might be explained by the bleomycin administration route used. Our intratracheal administration might have induced massive and early damage, compared with the subcutaneous route. Although the timing of these elevations was not consistent, our study and that of Leach et al. confirmed production of fibrotic mediators by endothelial cells from bleomycin-induced fibrotic lungs. Because these mediators directly recruit and activate fibroblasts to produce collagen, endothelial cells may contribute to the development of tissue fibrosis by producing such agents in response to bleomycin. Leach et al. also emphasized the contribution of endothelial cells to macrophage recruitment in inflammation-driven fibrosis and showed the up-regulation of $\mathrm{C}$ - $\mathrm{C}$ motif chemokine ligands and inflammatory mediators. We tested TNF- $\alpha$ expression as an inflammation related factor. In our model, the expression of TNF- $\alpha$ was elevated in endothelial cells at 7 days and sustained on day 21 after bleomycin administration, which indicates that inflammation was connected with our bleomycin-induced fibrosis.

As other fibrotic mediators, we examined expression of four PDGF receptor ligands. There were no significant differences in PDGF-A, B and D mRNA levels between endothelial cells from bleomycin-treated and saline-treated mouse lungs. In contrast, PDGF-C expression was elevated in endothelial cells from bleomycin-treated mouse lungs. TGF $-\beta$ further enhanced PDGF-C expression. PDGF is a potent mitogen for fibroblasts. Its overproduction can induce heart, liver and renal fibrosis. In the lung, PDGF-C expression was elevated in the bleomycin model, localized to patchy areas of lung fibrosis [34]. Various cell types, including epithelial, mesenchymal and inflammatory cells, were reported to produce PDGF-C, contributing to fibrosis [35]. In this study, we showed that PDGF-C expression was also elevated in endothelial cells during bleomycin-induced pulmonary fibrosis.

In addition to the production of fibrotic mediators, endothelial cells play critical roles in several physiological and pathological processes [12] through the activities of endothelium-derived relaxing and/or constricting factors. Two endothelium-derived relaxing factors, nitric oxide and PG- $\mathrm{I}_{2}$, are constitutively released by endothelial cells and their synthesis is increased in response to agonists [12]. Both agents have multiple effects, modulating
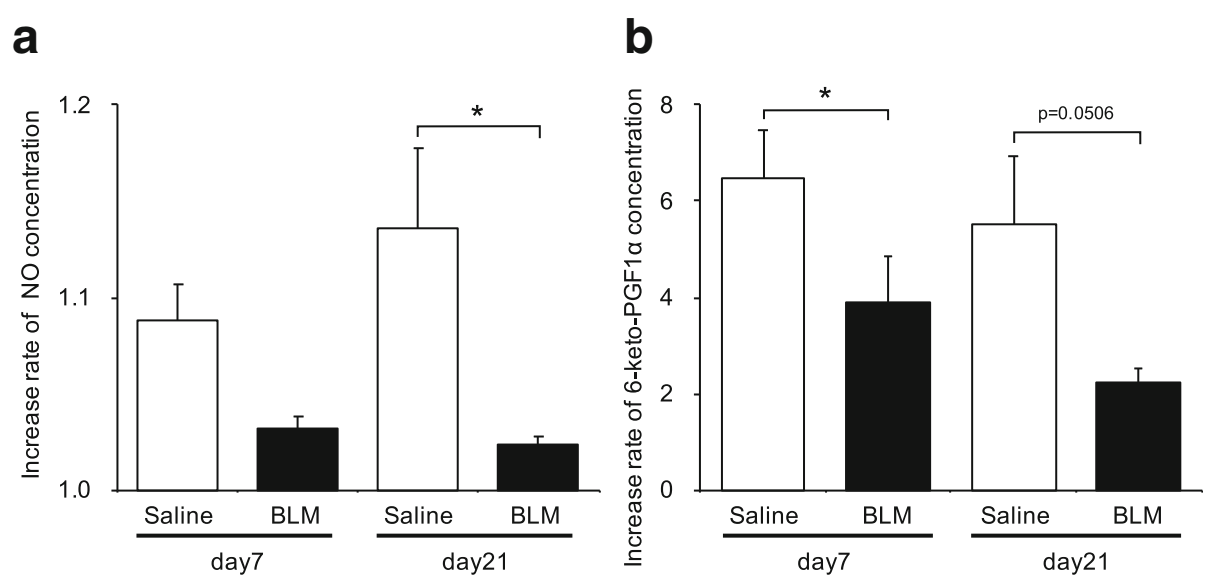

Fig. 7 Effects of TGF- $\beta$ on the functional properties of lung endothelial cells isolated from bleomycin-treated mice. a Intracellular nitric oxide response to TGF- $\beta$ was significantly attenuated in cells isolated on day 21 after bleomycin treatment ( $p=0.0138$, compared with cells from saline-treated mice). $\mathbf{b}$ The increase in 6-keto-PGF 1 la levels caused by TGF- $\beta$ was attenuated in cells isolated on day 7 or 21 from bleomycin-treated mice $(p=0.0206, p=0.0506$, respectively, compared with cells from saline-treated mice). Data are means \pm standard error, from three to four mice. ${ }^{*}, p<0.05$ 
platelet aggregation, inhibiting leukocyte adhesion and controlling vascular smooth muscle cell proliferation [36]. We examined production of nitric oxide and $\mathrm{PG}-\mathrm{I}_{2}$ in endothelial cells from bleomycin-induced fibrotic lung tissues. Although these cells produced nitric oxide and PG- $\mathrm{I}_{2}$ when stimulated with thapsigargin, the response in endothelial cells from fibrotic lungs was significantly weaker than in cells from normal lungs. Conversely, mRNA expression of iNOS was elevated, relative to the normal cells, in endothelial cells from bleomycin-induced fibrotic lungs. Because iNOS expression is stimulated by inflammation, increased expression of its transcript would be expected to occur after bleomycin administration. Almudever et al. showed that levels of tetrahydrobiopterin (BH4), a cofactor of NOS, were decreased in IPF, an effect that would lead to uncoupling of NOS activity [37]. Although $\mathrm{BH} 4$ levels were not examined in our experiments, it is possible that iNOS was uncoupled in the bleomycin-treated mouse lungs, leading to less nitric oxide formation and more oxidative stress. The weak nitric oxide response may have been related to the finding that eNOS knockout animals had prolonged fibrosis, compared with wildtypes, after bleomycin exposure [13].

In our study, we added TGF- $\beta$ to endothelial cells to determine whether it would induce additional changes in endothelial function. Regarding nitric oxide and $\mathrm{PG}-\mathrm{I}_{2}$ production, interestingly, TGF- $\beta$ further suppressed the weak nitric oxide and $\mathrm{PG}-\mathrm{I}_{2}$ production by endothelial cells from bleomycin-treated mouse lungs. However, TGF- $\beta$ did not affect levels of these mediators produced by cells from saline-treated control mice. Finder et al. showed that TGF- $\beta$ caused decreased nitric oxide production by rat pulmonary artery smooth muscle cells [38]. Our data indicated that inhibition of nitric oxide production by TGF- $\beta$ also occurred in pulmonary endothelial cells. Interestingly, TGF- $\beta$ enhanced the number of $\alpha$-SMA-positive cells and collagen production by endothelial cells from bleomycin-treated mouse lungs. TGF- $\beta$ stimulates type I collagen transcription, promotes synthesis of extracellular matrix components and is a central regulator of recruitment, activation and differentiation of myofibroblasts at the early stages of tissue repair $[16,27]$ and is highly involved in development of organ fibrosis [6]. We speculated that bleomycin pretreatment caused endothelial cells to be susceptible to further stimulation, by for example, TGF- $\beta$, as in our study. In our study, endothelial cells were substantially changed, functionally (collagen production) as well as phenotypically (transformed into $\alpha$-SMA positive cells) by both bleomycin exposure and TGF- $\beta$. In general, patients with pre-existing ILD are known to be at risk for acute exacerbation of ILD [39]. It is conceivable that bleomycin-induced fibrosis represents a priming state that is highly sensitive to any kind of stimulation and can then be readily driven to exacerbated fibrosis.
Another mechanism for endothelial cell participation in the pathogenesis of fibrosis, may involve secretion and deposition of excess collagen in tissues through the endothelial-mesenchymal transition. During the endothelialmesenchymal transition, endothelial cells lose their endothelial phenotype, such as expression of CD31 and vascular endothelial cadherin, and acquire a fibroblast-like mesenchymal phenotype, expressing $\alpha$-SMA, vimentin and type I collagen. Although several studies demonstrated that a partial epithelial-mesenchymal transition participated in pathologic fibrogenesis [40], there has been insufficient investigation of the role of myofibroblasts from the endothelial-mesenchymal transition in pulmonary fibrosis. Hashimoto et al. showed that areas of fibrotic involvement contained significant numbers of myofibroblasts originating from endothelial cells in bleomycin induced pulmonary fibrosis [41]. TGF- $\beta$ and activated Ras induced de novo $\alpha$-SMA expression in microvascular endothelial cells. We observed elevated expression of $\alpha$-SMA and Twist-1, a transcription factor involved in endothelial-mesenchymal transition [42], in endothelial cells from bleomycin-treated mouse lungs, indicating existence of an endothelial-mesenchymal transformation. Furthermore, adding TGF- $\beta$ significantly enhanced $\alpha$-SMA and Twist- 1 expression in such cells. TGF- $\beta$ induced mesenchymal transformation may be prominent in existing fibrosis. These findings, together, supported the conclusion that endothelial cells may adopt a fibroblast-like phenotype, through an endothelial-mesenchymal transformation, during fibrosis. In the present study, the connections between the nitric oxide pathway and this endothelial-mesenchymal transition remain unclear. Further studies are warranted to clarify the detailed mechanistic relationship between them.

\section{Conclusions}

Endothelial cells from lungs subjected to bleomycin-induced fibrosis were functionally altered and had a phenotype similar to that of myofibroblasts, potentially contributing to progression of pulmonary fibrosis. Pulmonary fibrosis is a lethal disease requiring elucidation of its mechanisms and, thereby, development of new therapies. A pathway involving endothelial cells may be a new therapeutic target for pulmonary fibrosis.

\section{Additional files}

\footnotetext{
Additional file 1: Figure S1. Purity of magnetically sorted mouse lung CD $45^{-} \mathrm{CD} 31^{+}$cells. The purity was confirmed using flow cytometry with antibodies to CD31 and CD45. Representative example of dot plots obtained from magnetically sorted mouse lung $\mathrm{CD}_{4} 5^{-} \mathrm{CD} 31^{+}$cells. Figures indicate percentages of cells expressing CD45 and CD31. The purity was > 90\% in the three experiments. (PDF $124 \mathrm{~kb}$ )
}

Additional file 2: Table S1. Primers used for quantitative real-time PCR. (DOCX 21 kb) 
Additional file 3: Figure S2. TGF- $\beta 1$ concentrations in BAL fluid after administration of bleomycin. TGF- $\beta 1$ concentrations in BAL fluid were gradually increased, with a significant increase on day 21 after bleomycin treatment $(p=0.0025$ and $p=0.0235$, compared with saline-treated mice and bleomycin-treated mice on day 7, respectively). (PDF $21 \mathrm{~kb}$ )

\section{Abbreviations}

BALF: Bronchoalveolar lavage fluid; BH4: Tetrahydrobiopterin; BLM: Bleomycin; CTGF: Connective tissue growth factor; DAF-FM/DA: 4-amino-5-methylamino-2',7'-difluorofluorescein diacetate; eNOS: Endothelial nitric oxide synthase; IL: Interleukin; ILD: Interstitial lung disease; iNOS: Inducible nitric oxide synthase; IPF: Idiopathic pulmonary fibrosis; MMP-12: Matrix metalloproteinase; PAl-1: Plasminogen activator inhibitor-1; PDGF: Platelet-derived growth factor; PG-1 $\mathrm{I}_{2}$ Prostaglandin $\mathrm{I}_{2}$; TGF$\beta$ : Transforming growth factor- $\beta$; TNF-a: Tumor necrosis factor- $\alpha$; UIP: Usual interstitial pneumonia; vWF: von Willebrand factor; a-SMA: a-smooth muscle actin

\section{Funding}

This work was supported by a Grant-in-Aid for Scientific Research.

\section{Availability of data and materials}

The datasets used and analyzed during the current study are available from the corresponding author upon reasonable request.

\section{Authors' contributions}

$\mathrm{NI}$ designed experiments, SK performed experiments and data analysis, SK and $\mathrm{NI}$ wrote the paper. AH, YS, NE, TF, YN, HW and TS provided intellectual contributions. All authors read and approved the final manuscript.

\section{Ethics approval and consent to participate}

This study was approved by the Animal Care and Use Committee of Hamamatsu University School of Medicine and all experiments were performed according to guidelines of this Committee.

\section{Consent for publication}

Not applicable.

\section{Competing interests}

The authors declare that they have no competing interests.

\section{Publisher's Note}

Springer Nature remains neutral with regard to jurisdictional claims in published maps and institutional affiliations.

\section{Received: 11 April 2018 Accepted: 14 June 2018}

\section{Published online: 26 June 2018}

\section{References}

1. American Thoracic S, European Respiratory S. American Thoracic Society/ European Respiratory Society international multidisciplinary consensus classification of the idiopathic interstitial pneumonias. This joint statement of the American Thoracic Society (ATS), and the European Respiratory Society (ERS) was adopted by the ATS board of directors, June 2001 and by the ERS executive committee, June 2001. Am J Respir Crit Care Med. 2002;165:277-304

2. Wolters PJ, Collard HR, Jones KD. Pathogenesis of idiopathic pulmonary fibrosis. Annu Rev Pathol. 2014;9:157-79.

3. King TE Jr, Pardo A, Selman M. Idiopathic pulmonary fibrosis. Lancet. 2011;378:1949-61

4. Bantsimba-Malanda C, Marchal-Somme J, Goven D, Freynet O, Michel L, Crestani B, Soler P. A role for dendritic cells in bleomycin-induced pulmonary fibrosis in mice? Am J Respir Crit Care Med. 2010;182:385-95.

5. Raghu G, Collard HR, Egan JJ, Martinez FJ, Behr J, Brown KK, Colby TV, Cordier JF, Flaherty KR, Lasky JA, et al. An official ATS/ERS/JRS/ALAT statement: idiopathic pulmonary fibrosis: evidence-based quidelines for diagnosis and management. Am J Respir Crit Care Med. 2011;183:788-824.

6. Rockey DC, Bell PD, Hill JA. Fibrosis-a common pathway to organ injury and failure. N Engl J Med. 2015;372:1138-49.
7. Bagnato G, Harari S. Cellular interactions in the pathogenesis of interstitial lung diseases. Eur Respir Rev. 2015;24:102-14.

8. Aird WC. Phenotypic heterogeneity of the endothelium: I. Structure, function, and mechanisms. Circ Res. 2007:100:158-73.

9. Takabatake N, Arao T, Sata M, Abe S, Inoue S, Shibata Y, Takeishi Y, Kubota I. Involvement of pulmonary endothelial cell injury in the pathogenesis of pulmonary fibrosis: clinical assessment by 123I-MIBG lung scintigraphy. Eur J Nucl Med Mol Imaging. 2005;32:221-8.

10. Magro CM, Waldman WJ, Knight DA, Allen JN, Nadasdy T, Frambach GE, Ross P, Marsh CB. Idiopathic pulmonary fibrosis related to endothelial injury and antiendothelial cell antibodies. Hum Immunol. 2006;67:284-97.

11. Iyer AK, Ramesh V, Castro CA, Kaushik V, Kulkarni YM, Wright CA, Venkatadri R, Rojanasakul Y, Azad N. Nitric oxide mediates bleomycininduced angiogenesis and pulmonary fibrosis via regulation of VEGF. J Cell Biochem. 2015:116:2484-93.

12. Michiels C. Endothelial cell functions. J Cell Physiol. 2003;196:430-43.

13. Chung MP, Monick MM, Hamzeh NY, Butler NS, Powers LS, Hunninghake GW. Role of repeated lung injury and genetic background in bleomycininduced fibrosis. Am J Respir Cell Mol Biol. 2003;29:375-80.

14. Yoshimura S, Nishimura Y, Nishiuma T, Yamashita T, Kobayashi K, Yokoyama M. Overexpression of nitric oxide synthase by the endothelium attenuates bleomycin-induced lung fibrosis and impairs MMP-9/TIMP-1 balance. Respirology. 2006;11:546-56.

15. Akamatsu T, Arai Y, Kosugi I, Kawasaki H, Meguro S, Sakao M, Shibata K, Suda T, Chida K, Iwashita T. Direct isolation of myofibroblasts and fibroblasts from bleomycin-injured lungs reveals their functional similarities and differences. Fibrogenesis Tissue Repair. 2013;6:15.

16. Thannickal VJ, Lee DY, White ES, Cui Z, Larios JM, Chacon R, Horowitz JC, Day RM, Thomas PE. Myofibroblast differentiation by transforming growth factor-beta1 is dependent on cell adhesion and integrin signaling via focal adhesion kinase. J Biol Chem. 2003;278:12384-9.

17. Piera-Velazquez S, Li Z, Jimenez SA. Role of endothelial-mesenchymal transition (EndoMT) in the pathogenesis of fibrotic disorders. Am J Pathol. 2011:179:1074-80

18. Fernandez IE, Eickelberg $\mathrm{O}$. The impact of TGF-beta on lung fibrosis: from targeting to biomarkers. Proc Am Thorac Soc. 2012;9:111-6.

19. B BM, Lawson WE, Oury TD, Sisson TH, Raghavendran K, Hogaboam CM. Animal models of fibrotic lung disease. Am J Respir Cell Mol Biol. 2013:49:167-79.

20. Della Latta V, Cecchettini A, Del Ry S, Morales MA. Bleomycin in the setting of lung fibrosis induction: from biological mechanisms to counteractions. Pharmacol Res. 2015;97:122-30.

21. Leach HG, Chrobak I, Han R, Trojanowska M. Endothelial cells recruit macrophages and contribute to a fibrotic milieu in bleomycin lung injury. Am J Respir Cell Mol Biol. 2013;49:1093-101.

22. Azambuja E, Fleck JF, Batista RG, Menna Barreto SS. Bleomycin lung toxicity: who are the patients with increased risk? Pulm Pharmacol Ther. 2005;18:363-6.

23. Manitsopoulos N, Nikitopoulou I, Maniatis NA, Magkou C, Kotanidou A, Orfanos SE. Highly selective Endothelin-1 receptor a inhibition prevents bleomycin-induced pulmonary inflammation and fibrosis in mice. Respiration. 2018;95:122-36.

24. Piguet PF, Collart MA, Grau GE, Kapanci Y, Vassalli P. Tumor necrosis factor/ cachectin plays a key role in bleomycin-induced pneumopathy and fibrosis. J Exp Med. 1989:170:655-63.

25. Lasky JA, Ortiz LA, Tonthat B, Hoyle GW, Corti M, Athas G, Lungarella G, Brody A, Friedman M. Connective tissue growth factor mRNA expression is upregulated in bleomycin-induced lung fibrosis. Am J Phys. 1998;275:L365-71.

26. Hoshino T, Okamoto M, Sakazaki Y, Kato S, Young HA, Aizawa H. Role of proinflammatory cytokines IL-18 and IL-1 beta in bleomycin-induced lung injury in humans and mice. Am J Respir Cell Mol Biol. 2009;41:661-70.

27. Selman $M$, King TE, Pardo A, American Thoracic $S$, European Respiratory $S$. American College of Chest P: idiopathic pulmonary fibrosis: prevailing and evolving hypotheses about its pathogenesis and implications for therapy. Ann Intern Med. 2001:134:136-51.

28. Broekelmann TJ, Limper AH, Colby TV, McDonald JA. Transforming growth factor beta 1 is present at sites of extracellular matrix gene expression in human pulmonary fibrosis. Proc Natl Acad Sci U S A. 1991;88:6642-6.

29. Khalil N, O'Connor RN, Unruh HW, Warren PW, Flanders KC, Kemp A, Bereznay $\mathrm{OH}$, Greenberg AH. Increased production and 
immunohistochemical localization of transforming growth factor-beta in idiopathic pulmonary fibrosis. Am J Respir Cell Mol Biol. 1991;5:155-62.

30. Santana A, Saxena B, Noble NA, Gold LI, Marshall BC. Increased expression of transforming growth factor beta isoforms (beta 1, beta 2, beta 3) in bleomycin-induced pulmonary fibrosis. Am J Respir Cell Mol Biol. 1995;13:34-44.

31. Giri SN, Hyde DM, Hollinger MA. Effect of antibody to transforming growth factor beta on bleomycin induced accumulation of lung collagen in mice. Thorax. 1993;48:959-66.

32. Zhang K, Flanders KC, Phan SH. Cellular localization of transforming growth factor-beta expression in bleomycin-induced pulmonary fibrosis. Am J Pathol. 1995;147:352-61.

33. Yan LF, Wei YN, Nan HY, Yin Q, Qin Y, Zhao X, Chen BY, Zhao G, Wei JG, Cu GB. Proliferative phenotype of pulmonary microvascular endothelial cells plays a critical role in the overexpression of CTGF in the bleomycin-injured rat. Exp Toxicol Pathol. 2014;66:61-71.

34. Zhuo Y, Zhang J, Laboy M, Lasky JA. Modulation of PDGF-C and PDGF-D expression during bleomycin-induced lung fibrosis. Am J Physiol Lung Cell Mol Physiol. 2004;286:L182-8.

35. Klinkhammer BM, Floege J, Boor P. PDGF in organ fibrosis. Mol Asp Med. 2017.

36. Asai M, Takeuchi K, Saotome M, Urushida T, Katoh H, Satoh H, Hayashi H, Watanabe $\mathrm{H}$. Extracellular acidosis suppresses endothelial function by inhibiting store-operated Ca2+ entry via non-selective cation channels. Cardiovasc Res. 2009;83:97-105.

37. Almudever P, Milara J, De Diego A, Serrano-Mollar A, Xaubet A, Perez-Vizcaino F, Cogolludo A, Cortijo J. Role of tetrahydrobiopterin in pulmonary vascular remodelling associated with pulmonary fibrosis. Thorax. 2013;68:938-48.

38. Finder J, Stark WW Jr, Nakayama DK, Geller D, Wasserloos K, Pitt BR, Davies P. TGF-beta regulates production of NO in pulmonary artery smooth muscle cells by inhibiting expression of NOS. Am J Phys. 1995;268:L862-7.

39. Enomoto Y, Inui N, Kato T, Baba T, Karayama M, Nakamura Y, Ogura T, Suda T. Low forced vital capacity predicts cytotoxic chemotherapy-associated acute exacerbation of interstitial lung disease in patients with lung cancer. Lung Cancer. 2016;96:63-7.

40. Lovisa S, LeBleu VS, Tampe B, Sugimoto H, Vadnagara K, Carstens JL, Wu CC, Hagos Y, Burckhardt BC, Pentcheva-Hoang T, et al. Epithelial-tomesenchymal transition induces cell cycle arrest and parenchymal damage in renal fibrosis. Nat Med. 2015;21:998-1009.

41. Hashimoto N, Phan SH, Imaizumi K, Matsuo M, Nakashima H, Kawabe T, Shimokata K, Hasegawa Y. Endothelial-mesenchymal transition in bleomycin-induced pulmonary fibrosis. Am J Respir Cell Mol Biol. 2010:43:161-72

42. Mammoto T, Muyleart M, Konduri GG, Mammoto A. Twist1 in hypoxiainduced pulmonary hypertension through transforming growth factor-betaSmad signaling. Am J Respir Cell Mol Biol. 2018;58:194-207.

\section{Ready to submit your research? Choose BMC and benefit from:}

- fast, convenient online submission

- thorough peer review by experienced researchers in your field

- rapid publication on acceptance

- support for research data, including large and complex data types

- gold Open Access which fosters wider collaboration and increased citations - maximum visibility for your research: over $100 \mathrm{M}$ website views per year

At BMC, research is always in progress.

Learn more biomedcentral.com/submissions 